\title{
Design, fabrication and calibration of a low cost smart sap flow measuring system based on ATmega 328/P microcontroller.
}

\author{
Prince Dangare $^{1}$, Teddious Mhizha ${ }^{2}$, Emmanuel Mashonjowa $^{3}$ \\ \{dangareprince@gmail.com ${ }^{1}$, tmhizha@gmail.com ${ }^{2}$, \\ emashonjowa@gmail.com $\left.{ }^{3}\right\}$ \\ \{pdangare@science.uz.ac.zw ${ }^{1}$, tmhizha@science.uz.ac.zw² ${ }^{2}$, \\ emash@science.uz.ac.zw $\left.{ }^{3}\right\}$
}

University of Zimbabwe, Department of Physics, 100 Churchill Road, P.O. Box MP 167 Mount Pleasant, Harare, Zimbabwe $e^{1,2,3}$.

\begin{abstract}
A microcontroller driven sap flow measuring system was designed and constructed for automating the measurement and recording of sap flow in plants. The system comprise of an ATmega 328/P microcontroller which forms the heart of the controlling circuit, real time clock for providing timestamps to the measured data and an external secure digital card for storing measured sap flow data. The system uses a thermal dissipation sap flow sensor for measuring sap flow and this was fabricated using hypodermic needles and type-T thermocouples, making the fabrication procedure inexpensive. The total cost for constructing the sap flow system was US \$72.64 excluding labor costs. The system was calibrated and tested over a fortnight period on a fountain tree. The calibration graph indicated a linear relationship between the actual sap flow rate measured using the dynagage sap flow sensor and the sap flow rate measured using the thermal dissipation sap flow sensor, with a good coefficient of determination value of 0.8211 . The calibration graph produced a calibration multiplier of 18.542 with an offset value of $124.4 \mathrm{~g} / \mathrm{h}$. The system produced satisfactory results with a good storage of the measured data over the duration of the experiment. It was concluded that the smart sap flow measuring system is suitable for measuring sap flow rate in trees.
\end{abstract}

Keywords: Calibration, data logging, field testing, sap flow, sap flow sensor, microcontroller.

ACRID 2017, June 20-21, Victoria Falls, Zimbabwe

Copyright (C) 2017

DOI 10.4108/eai.20-6-2017.2275846 


\section{Introduction}

The unsurprising future rise in the frequency and severeness of droughts in various regions of the world including Southern Africa due to global climate change and ever rising competition between water users [3] is posing a serious threat to the agricultural sector. Monitoring plant water status is one way of optimizing irrigation water. This method employs an attribute of the plant that respond to water stress [7], so that irrigation will be carried out according to the actual plant water needs [11] hence conserving water. The traditional methods of calculating irrigation quantity based on environmental variables can be difficult to use and are imprecise at best. Sap flow is one plant based indicator that show good prospects for determining plant water requirements [10]. Precise and accurate measurement of sap flow is very vital in estimating whole plant transpiration [1], hence quantifying plant water use. The most common sap flow measuring techniques include heat pulse [13], stem segment heat balance [2], thermal dissipation [5] and heat deformation [9]. The above techniques measure sap flow using commercial state of the art sensors and the measured data is stored in advanced logging systems. These devices measure and store sap flow data with high accuracy. Most advanced logging systems use expensive programmable logic controllers (PLCs) which are the most ideal controllers. The cost of commercially available sap flow measuring systems is beyond the reach of many small holder farmers who occupy pieces of land in arid to semi-arid areas hence limiting their applicability to improve water use efficiency. An alternative to PLCs which show good prospects are ATmega 328/P integrated chips. The ATmega 328/P microcontroller use a cheap 8-bit, low processing power, small working memory and small storage capacity, requires minimal human-computer interaction, uses low cost sensors and simple circuitry, consuming less electrical power, thus making the system low cost [6]. Furthermore, an ATmega 328/P microcontroller is able to store real time data in an external secure digital storage memory, making itself a good tool for low cost systems. The aim of this study was to design, fabricate and calibrate a low cost sap flow measuring system which is controlled by an ATmega 328/P microcontroller and using thermal dissipation sap flow sensor. Included in the design criteria were automated measurements, data collection and storage, low cost, ease of manufacture and reliable performance.

\section{Description of the sap flow measuring system}

A circuit was designed to automate measurements and record tree sap flow velocity. The circuit is based on a programmable ATmega 328/P microcontroller, with peripheral components connected to and controlled by the microcontroller. The system uses a thermal dissipation sap flow sensor because it is of low cost and easy to manufacture. Circuit components used in this design were readily available, inexpensive, interfaced easily with the ATmega 328/P microcontroller, operated on low DC voltages and provided the desired functions. 


\subsection{Circuit design}

The main components of the circuit are an Arduino Uno board with ATmega 328/P microcontroller, real time clock, secure digital shield and card, liquid crystal display screen, precision amplifier, potentiometer and resistors. A design schematic of the circuit is shown in Fig. 1.

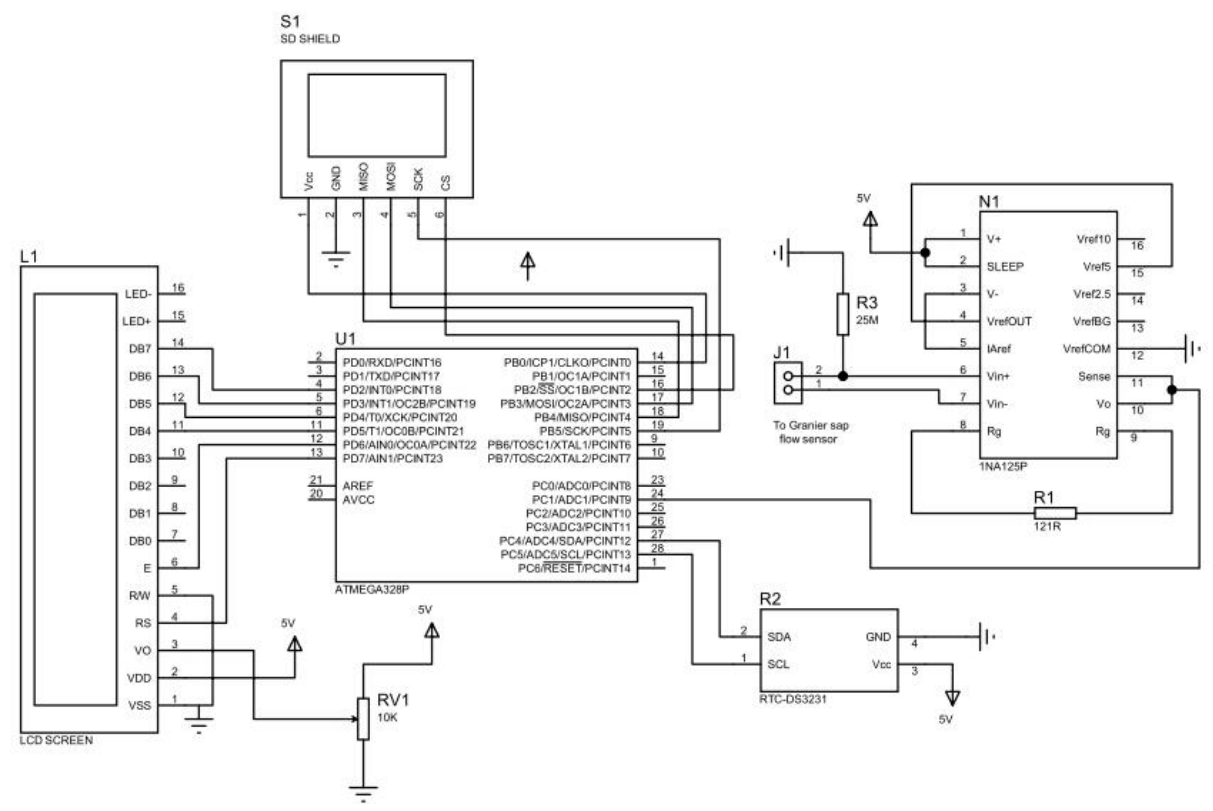

Fig. 1. The smart sap flow measuring system control circuit schematic.

The microcontroller is programmed using Arduino integrated development environment software. Date and time stamps for the recorded data is provided by a real time clock. Since the ATmega 328/P microcontroller has a limited storage space, measured data is stored in a secure digital card. A precision instrumentation amplifier, INA125P (Texas instruments, Dallas, TX) is used to amplify very small voltage signals coming from the sap flow sensor. The input impedance of the INA125P amplifier is extremely high [16], thus to avoid amplifier saturation an input Common-Mode Current Path was provided by connecting a resistor on the noninverting terminal of the differential amplifier to the ground. A $16 \times 2$ liquid crystal display is used to display the progress of measured parameters and any system's malfunctions. The voltage regulator on the Arduino Uno board is used to supply voltage to the circuit components.

\subsection{Thermal dissipation sap flow sensor theory of operation}

The thermal dissipation sap flow probe consists of a pair of stainless steel needles which are installed into the tree sapwood about $40 \mathrm{~mm}$ apart in a vertical line. The upper needle contains a resistor and a T-type (copper-constantan) thermocouple junction that is referenced to another lower unheated needle containing another T-type thermocouple junction. The resistor 
in the upper needle is supplied with a constant voltage. A difference in temperature, $\Delta \mathrm{T}$ is created between the heated and reference probes, that is dependent on the rate at which sap flows around the probes. As sap flow rate increases, the heated needle cools quickly and $\Delta \mathrm{T}$ decreases, whereas on the other hand as sap flow rate decreases, $\Delta \mathrm{T}$ increases as heat is dissipated slowly on the heated needle [8], [12]. Experiments have shown [12] that a relationship exists between the observed temperature difference and the sap flow velocity according to equation 1 .

$$
V=0.0119\left(\frac{\Delta T_{\max }-\Delta T}{\Delta T}\right)^{1.231}
$$

Where $\mathrm{V}$ is the average sap flow velocity along the length of the probe in $c m s^{-1}, \Delta \mathrm{T}$ is the temperature difference observed between the heated and reference needles and $\Delta T_{\text {max }}$ is the value of $\Delta \mathrm{T}$ when there is no sap flow. Equation 1 applies when the entire lenght of the sap flow probe is in contact with the sapwood. A correction for equation 1 is required when the heated probe exceeeds the thickness of sapwood, as this under estimates sap velocity. For that case $\Delta \mathrm{T}$ of equation 1 is replaced with a corrected tempearture difference of the sapwood, $\Delta T_{s w}$ as:

$$
\Delta T_{S W}=\frac{\Delta T-\left(b \times \Delta T_{\max }\right)}{a}
$$

Where $\mathrm{a}$ and $\mathrm{b}$ are the proportions of the probe in sapwood and inactive xylem respectively, where $b=1-a$. The power delivered to the heated needle is calculated using equation 3 :

$$
P=\frac{V^{2}}{R_{\text {coil }}}
$$

Where $\mathrm{P}$ is the electrical power, $\mathrm{V}$ is the regulated voltage and $R_{\text {coil }}$ is the resistance of the heater coil inside the heated needle.

To convert the sap flow velocity into mass sap flow rate, $\mathrm{F}(\mathrm{g} / \mathrm{h})$, an estimate of sap-conducting cross sectional area, $A_{s}$ is required so that:

$$
F=3600 V A_{s} \rho_{s}
$$

Where $\rho_{s}$ is the density of sap.

For young potted navel orange trees, the conducting sapwood area and the stem cross sectional area are related by a linear relationship as in equation 5 [4].

$$
y=0.8331 x
$$

Where $y$ is the sapwood area $\left(\mathrm{cm}^{2}\right)$ and $x$ is the stem $\operatorname{area}\left(\mathrm{cm}^{2}\right)$.

\subsection{Thermal dissipation sap flow sensor fabrication}

The sensor uses the principle of heat dissipation by the sapwood from a heated needle which is referenced to the sapwood temperature below the heated needle. In order to make the sap flow sensor, two $10 \mathrm{~mm}$ long 18 gauge hypodermic needles were cut using a Dremmel tool. The needles were cleaned inside by running a metal wire repeatedly through them. Two $5 \mathrm{~cm}$ long copper-constantan thermocouple wires were cut and about $5 \mathrm{~mm}$ of insulation material were removed from each end of the thermocouple wires. The cut pieces of thermocouple wires 
were used to make Type-T thermocouples using spot welding. A digital voltmeter was used to measure the resistance between two leads of each thermocouple as a way to check the proper formation of thermocouple junctions. The exposed thermocouple ends carrying thermocouple junctions were completely coated with spray paint in order to insulate them. About $6 \mathrm{~cm}$ length of $0.1 \mathrm{~mm}$ enamelled nickel-chrome heating wire was cut and a coil was formed around one of the thermocouples paint insulated end. The thermocouple end carrying the heating wire and the other without, were inserted approximately half way into the cut hypodermic needles in order to form a heated and reference needles respectively. Two drops of cyanoacrylate adhesive were introduced through the open end of each needle. The base and open end of each needle were sealed with epoxy adhesive in order to hold the thermocouples and heating wire in place and also prevent water reaching the thermocouple junctions. After the epoxy adhesive set, the needle casing and thermocouple for each sensor were tested for continuity since if any continuity was observed between the two, the sensor had to be discarded. Constantan wires from the reference and heated needles were connected together by twisting their bare ends. A four stranded cable with a waterproof connector on one end was soldered onto the two free ends of the heater wire, the thermocouple copper wires of the two sensors respectively. The soldered joints, heater wire and thermocouple wires were covered with a heat shrink tube for additional protection and to avoid short circuits (see Fig. 2). The heated needle voltage was set using equation 3.

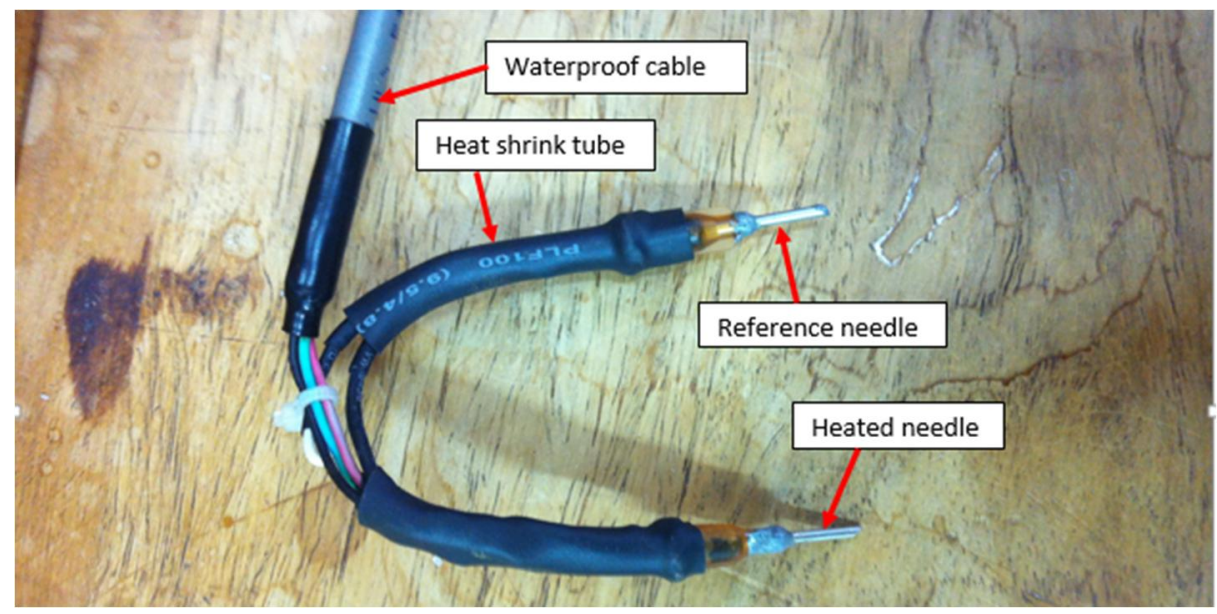

Fig. 2. The fabricated sap flow sensor.

\subsection{Circuit operation}

The circuit was designed to operate from low DC voltages $(7 \mathrm{~V}$ minimum and $14 \mathrm{~V}$ maximum). The microcontroller was programmed to control all measurements including user interface functions and data storage. The heated needle of the sap flow sensor delivers a constant $0.1 \mathrm{~W}$ of power. The output of the sap flow sensor is first amplified by an instrumentation amplifier so that its output signals can be read by the microcontroller. Sap flow measurements are taken every 30 seconds and time stamps (month, day, year, hour, minutes and seconds) are provided by the real time clock incorporated in the circuit. Measured sap flow data including time stamps are stored in the secure digital card as comma separated variables. Cost of the sap 
flow measuring system circuit and sensor components are shown in Table 1. Complete sap flow measuring system costed US \$72.64 excluding labor costs.

Table 1. List of Sap Flow measuring system components and costs

\begin{tabular}{ll}
\hline Description & $\begin{array}{c}\text { Cost } \\
\text { (US\$) }\end{array}$ \\
\hline Arduino Uno R3 (ATmega 328 assembled) & 19.95 \\
1NA125P Instrumentation Amplifier & 7.85 \\
Two hypodermic needles, 18 Gauge & 4.00 \\
DS3231 RTC & 5.89 \\
SD Card Reader & 6.00 \\
SanDisk 2 GB Class 4 SDHC Memory Card & 4.00 \\
16 x 2 LCD & 9.95 \\
Miscellaneous (resistors, water proof connectors, connection cables, copper- & 15.00 \\
constantan wire, heat shrink tube, cyanoacrylate adhesive, spray paint etc.) & \\
Total & 72.64 \\
\hline
\end{tabular}

\section{Field testing and calibration of the sap flow measuring system}

The following section describe the experimental location and experimental setup during the field testing of the sap flow measuring system.

\subsection{Experimental setup}

This study was carried out on an open-air laboratory at the Department of Physics, University of Zimbabwe Mt. Pleasant Campus, Harare, Zimbabwe. The site is situated approximately $31.1^{\circ} \mathrm{E}$ and $17.8^{\circ} \mathrm{S}$ and an altitude of approximately $1483 \mathrm{~m}$ above mean sea level. Two $10 \mathrm{~mm}$ deep holes and $40 \mathrm{~mm}$ apart were drilled onto a Spathodea campanulata 'Fountain tree'. The drilled bottom hole was set approximately $30 \mathrm{~cm}$ above the soil surface to prevent thermal gradients caused by cool sap emerging from the soil. The heated needle of the thermal dissipation sap flow sensor was inserted at the top hole whilst the reference needle was inserted at the bottom hole. To add thermal insulation and avoid bending stresses, foam quarter eggs were installed on either side of the thermal dissipation sap flow sensor using an adhesive tape, tightly wrapped around the foam eggs and the tree stem. Reflective bubble insulation was wrapped around the thermal dissipation sap flow sensor installation to avoid direct sunlight reaching the sensor. The upper and lower ends of the reflective bubble insulation was tightly bound to the tree's stem by an adhesive tape (see Fig.3). The thermal dissipation sap flow sensor was connected to the smart sap flow control circuit which was programmed to sample and store readings every 30 seconds. Dynagage sap flow sensor (SGB35, Dynamax Inc., USA) was mounted approximately $30 \mathrm{~cm}$ above the heated needle of the thermal dissipation probe to 
prevent the needle heating from affecting the dyanagage readings. The dyanagage installation was wrapped with a reflective bubble insulation to prevent sunlight from affecting the sensistive energy balance readings and the upper and lower ends of the reflective bubble insulation were tightly bound to the tree's stem using an adhesive tape (see Fig.3). The dynagage was connected to a data logger (CR23X, Campbell Scientific Ltd., Logan, USA) which was programmed to sample readings every 5 seconds and store minute averages. Stem above the dyangage installation was tripple wrapped with aluminum foil. This was done to prevent inconsistent results by equalizing temperatures of the stem to the ambient, since sun struck the stem at various times of the day.

\subsection{Thermal dissipation sap flow measuring system calibration}

Fortnight simultaneous measured sap flow data for the thermal dissipation sap flow sensor and dynagage sap flow sensor were downloaded from the secure digital card on the microcontroller system and CR23X data logger respectively. The downloaded files were opened in Microsoft Excel spreadsheet. Mass sap flow rate measured using the thermal dissipation sap flow sensor was calculated using equation 4, whilst sap flow velocity and sapwood area were calculated using equations 1 and 5 respectively. Mass sap flow rate measured using the dynagage sap flow sensor was calculated using the stem heat balance equation [17]. Calculated mass sap flow rate for the two measurement techniques were integrated in hourly intervals. A calibration graph of standard sap flow rate measured using the dynagage sap flow sensor was plotted against the sap flow measured using the thermal dissipation sap flow sensor as in Figure 4 [15]. The calibration equation was used to correct the sap flow data measured using the thermal dissipation sap flow sensor. 


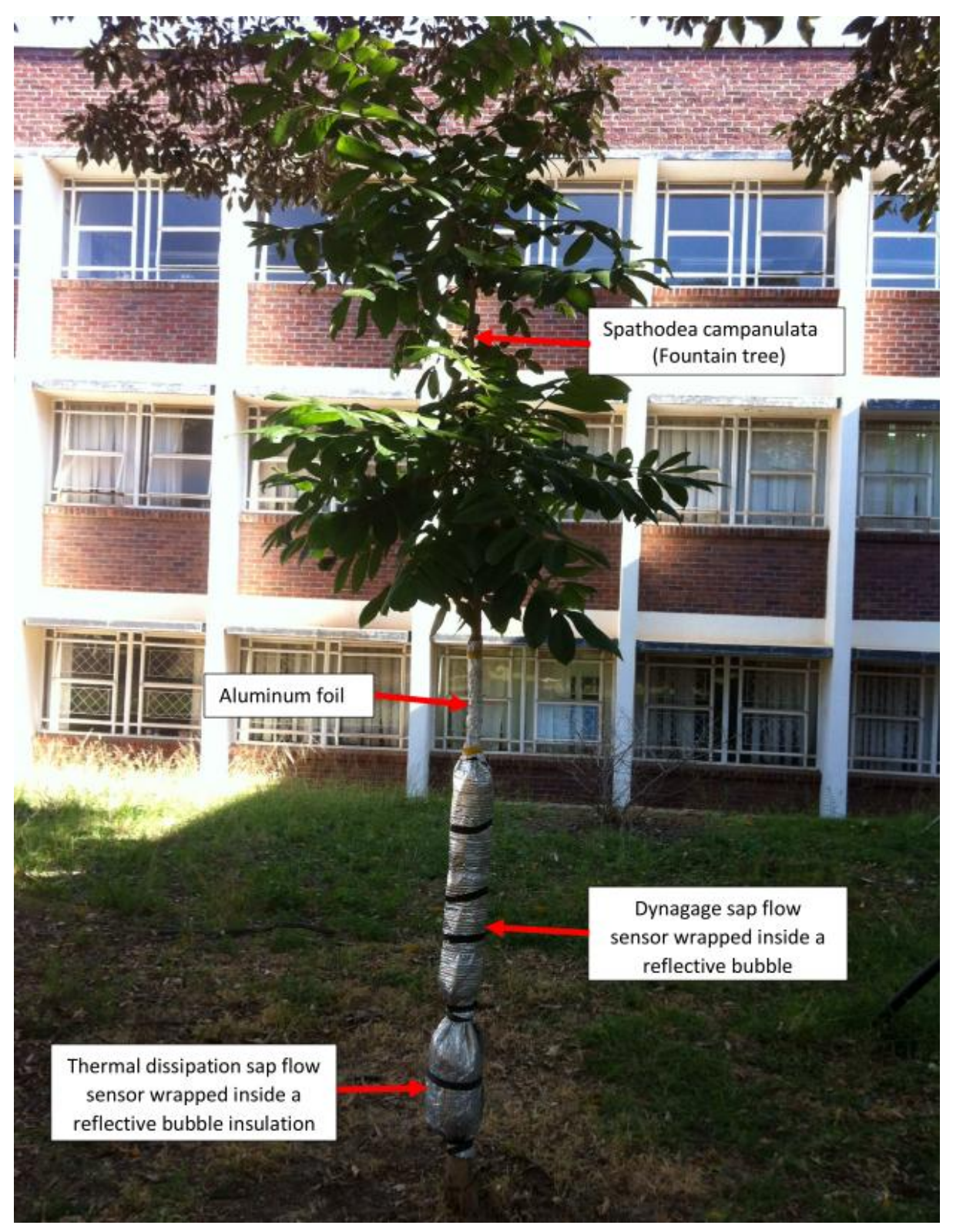

Fig. 3. The experimental setup used to calibrate the sap flow measuring system. 


\section{Results and Discussion}

Figure 4 shows the calibration graph of the sap flow sensor for the two weeks period from 25 May 2017 to 7 June 2017. Figure 5 shows the relationship between the vapor pressure deficit, solar radiation and the average hourly sap flow rate on a clear sunny day during the calibration period.

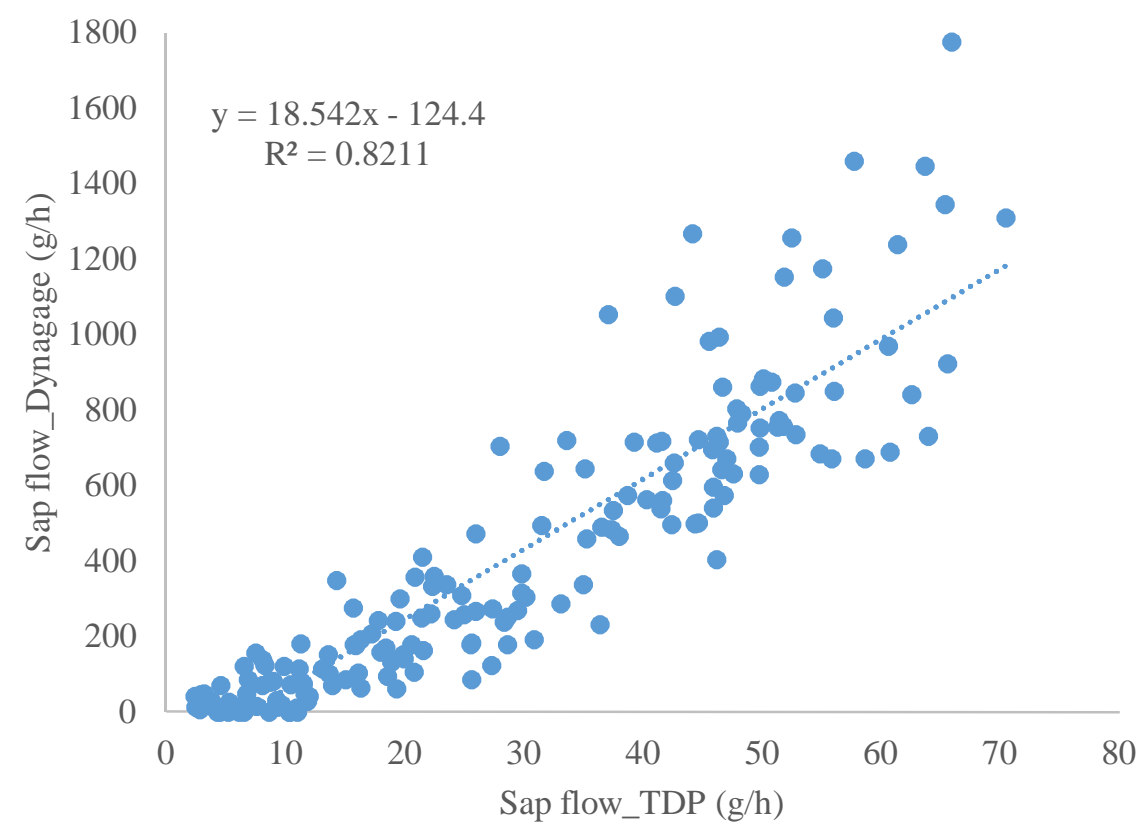

Fig. 4. Sap flow sensor calibration graph 
The calibration graph (see Fig.4) showed a linear trend between the actual sap flow rate measured using the dynagage sap flow sensor and sap flow rate measured using the smart sap flow sensor (thermal dissipation sap flow sensor). A good coefficient of determination value of 0.8211 implied that most $(82.11 \%)$ of the variation in thermal dissipation sensor output can be associated with the plant sap flow rate. From the calibration equation, the calibration multiplier was 18.542 with an offset value of $124.4 \mathrm{~g} / \mathrm{h}$. The linear relationship between the measured sap flow rate using the smart sap flow sensor and the actual sap flow rate enables the smart sap flow system suitable for measuring sap flow rate in trees. However, the calculated sap flow rate from the thermal dissipation sensor was lower than the calculated sap flow rate from the dynagage sap flow sensor. This may be related to the fact that sapwood area used to calculate mass sap flow rate for the thermal dissipation probe was derived from literature and not accurately determined for the tree species used. In addition, thermal dissipation sap flow sensor is known to seriously under estimate sap flux density [14], hence calibration procedure is very essential before using it.

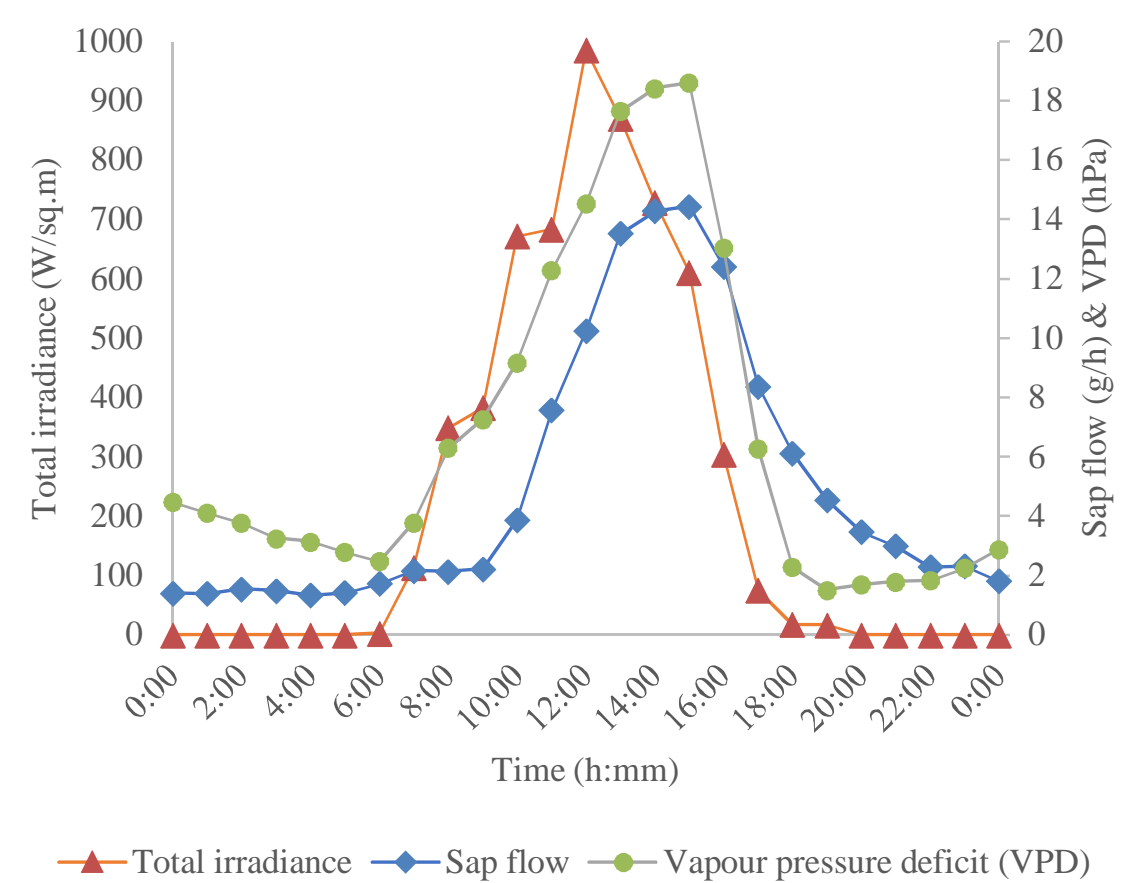

Fig. 5. An example of plant response to the environment on a clear sunny day, manifested in stem sap flow rate.

The tree's sap flow in Figure 5 showed a steady increase from dawn to a maximum between $1300 \mathrm{hrs}$ and $1500 \mathrm{hrs}$, then a steady decrease until dusk. This indicated low sap flow rates during the night and high sap flow rates during the day. This is because solar radiation and vapor pressure deficit are the key climatic factors that drive transpiration in plants. From the Figure 5, high vapor pressure deficit and solar radiation corresponded with high sap flow rates. On the other hand, low solar radiation and vapor pressure deficit resulted in low sap flow rates. 


\section{Conclusion}

A microcontroller driven smart sap flow measuring system was designed. The system uses a thermal dissipation sap flow sensor for measuring sap flow. The sap flow measuring system consists of cheap electronic components and was designed for continuous automated measurements. The complete sap flow measuring system costed US \$72.64 excluding labor costs. The system was calibrated and tested over a fortnight period on a fountain tree. The calibration graph indicated a linear relationship between the actual sap flow rate measured using the dynagage sap flow sensor and the sap flow rate measured using the smart sap flow sensor (thermal dissipation sap flow sensor), with a good coefficient of determination value of 0.8211 . The calibration graph produced a calibration multiplier of 18.542 with an offset value of 124.4 $\mathrm{g} / \mathrm{h}$. The smart sap flow measuring system produced satisfactory and valid results on the plant's sap flow rate measurements, hence it is suitable for measuring sap flow rate in trees.

Acknowledgements. Part of this work was supported by the University of Zimbabwe Research Board.

\section{References}

[1] Chang, X., Wenzhi, Z., Zhibin, H.: Radial pattern of sap flow and response to microclimate and soil moisture in Qinghai spruce (Picea crassifolia) in the upper Heihe River Basin of arid northwestern China. Agricultural and Forest Meteorology.187, 14-21(2014)

[2] Cienciala, E., Lindroth, A., Čermák, J., Hallgren, J. -E., Kuèera, J.: Assessment of transpiration estimates for Picea abies trees during a growing season.Trees.6,121-127(1992)

[3] Dzikiti, S., Verreynne, S. J., Stuckens, J., Strever, A., Verstraeten, W. W., Swennen, R., Theron, K. I., Coppin, P.: Seasonal variation in canopy reflectance and its application to determine the water status and water use by citrus trees in the Western Cape, South Africa. Agricultural and Forest Meteorology.151,1035-1044(2011)

[4] Dzikiti, S.: Stomatal oscillation and the response of citrus trees to different irrigation strategies in northern Zimbabwe. Doctor of Philosophy Thesis, Gent University (2007)

[5] Granier, A.: A new method of sap flow measurement in tree stems. Ann. Sci. For.42,193-200 (1985)

[6] Groener, B., Knopp, N., Korgan, K., Perry, R., Romero, J., Smith, K., Stainback, A., Strzelczyk, A., Henriques, J.: Preliminary design of a low - cost greenhouse with open source control systems. Procedia Engineering.107,470-479(2015)

[7] Jones, H. G.: Irrigation scheduling: Advantages and pitfalls of plant-based methods. J. Exp. Bot.55(407),2427-2436(2004)

[8] Lu, P., Laurent, U., Ping, Z.: Granier's Thermal Dissipation Probe (TDP) Method for Measuring Sap Flow in Trees: Theory and Practice. Acta Botanica Sinica.46(6),631-646(2004)

[9] Meiresome, L., Nadezhdina, N., Čermák, J., Van Slycken, J., Ceulemans, R.: Transpiration of a monoclonal poplar stand in Flanders (Belgium). Agric. For. Meteorol.96,65-179(1999)

[10] Ortuno, M. F., Alarcon, J. J., Nicolas, E., Torrecillas, A.: Sap flow and trunk diameter fluctuations of young lemon trees under water stress and rewatering. Environmental and Experimental Botany. $54,155-162(2005)$ 
[11] Patakas, A., Noitsakis, B., Chouzouri, A.: Optimization of irrigation water use in grapevines using the relationship between transpiration and plant water status. Agriculture, Ecosystems and Environment.106,253-259(2005)

[12] Smith, D. M., Allen, S. J.: Measurement of sap flow in plant stems. Journal of experimental Botany.47(305),1833-1844(1996)

[13] Swanson, R. H., Whitfield, D. W. A.: A numerical analysis of heat pulse velocity theory and practice. J. Exp. Bot.32,221-239(1981)

[14] Vandegehuchte, M. W., Steppe, K.: Sap flow +: a four-needle heat-pulse sap flow sensor enabling nonempirical sap flux density and water content measurements. New Phytologist.1-12(2012)

[15] A Thermal Dissipation Sap Velocity Probe for Measurement of Sap Flow in Plants, http://dynamax.com

[16] INA125 Instrumentation Amplifier With Precision Voltage Reference, http://www.ti.com

[17] Dynagage Installation and operation manual, http://dynamax.com 